\section{IGDA. 2: Interviewing the patient}

\author{
IGDA WORKGROUP, WPA
}

\section{1}

An appropriate setting for the psychiatric interview should be selected or arranged within the circumstances available. It should be as comfortable as possible for both patient and interviewer, protect privacy, and minimise external distractions.

\section{2}

A trusting rapport with the patient should be established by introducing oneself, greeting the patient appropriately, explaining the purpose of the interview, ensuring confidentiality to the extent possible, and communicating an intention to be of help.

\section{3}

The interview is a dynamic process, which should lead to mutual understanding between clinician and patient without blurring their respective roles. The clinician should adopt an attentive, interested, listening attitude, convey respect for the patient's wishes and dignity, strive to create a natural conversational flow, and facilitate the engagement of the patient in the interview (Fig. 2.1).

\section{4}

Cultural considerations should inform the conduct of the interview. The clinician and patient should discuss cultural issues and opportunities for advancement, as well as language barriers, and agree on ways to deal with them. Whenever necessary, competent and thoughtful translators and cultural consultants (who can be trusted not to undermine the clinician-patient engagement) should be enlisted.

\section{5}

The clinician should explore the circumstances leading to the presentation for evaluation, and the patient's expectations

\title{
2.7
}

The clinician should obtain systematic information on other important aspects of the patient's clinical background, including family, developmental, social, occupational, substance use, and general medical histories.

\section{8}

The clinician should endeavour to maintain a collaborative rapport with the patient, leading to the formulation of a jointly agreed care plan.

for care. Gaining an understanding of patient's life history and concerns for quality of life is also important. Patients should be encouraged to express themselves in the way they prefer.

\section{6}

Through anamnesis, information should be systematically gathered on the major mental health problems of the patient, including the time frame, mode and circumstances of onset, clinical signs and symptoms, dangerous behaviours, concomitant functional difficulties, relevant contextual factors, illness course, treatment received, and efforts to restore health and quality of life (from physical well-being to spirituality).

\section{9}

Towards the end of the interview the subsequent diagnostic and therapeutic steps should be specified. Further diagnostic efforts may include - as appropriate, and with the patient's consent to the fullest possible extent - interviewing family members and other individuals knowledgeable about the patient's condition, as well as using supplementary assessment instruments and procedures.

\subsection{0}

The clinician should work with the patient towards closing the interview in a manner that promotes in the patient greater

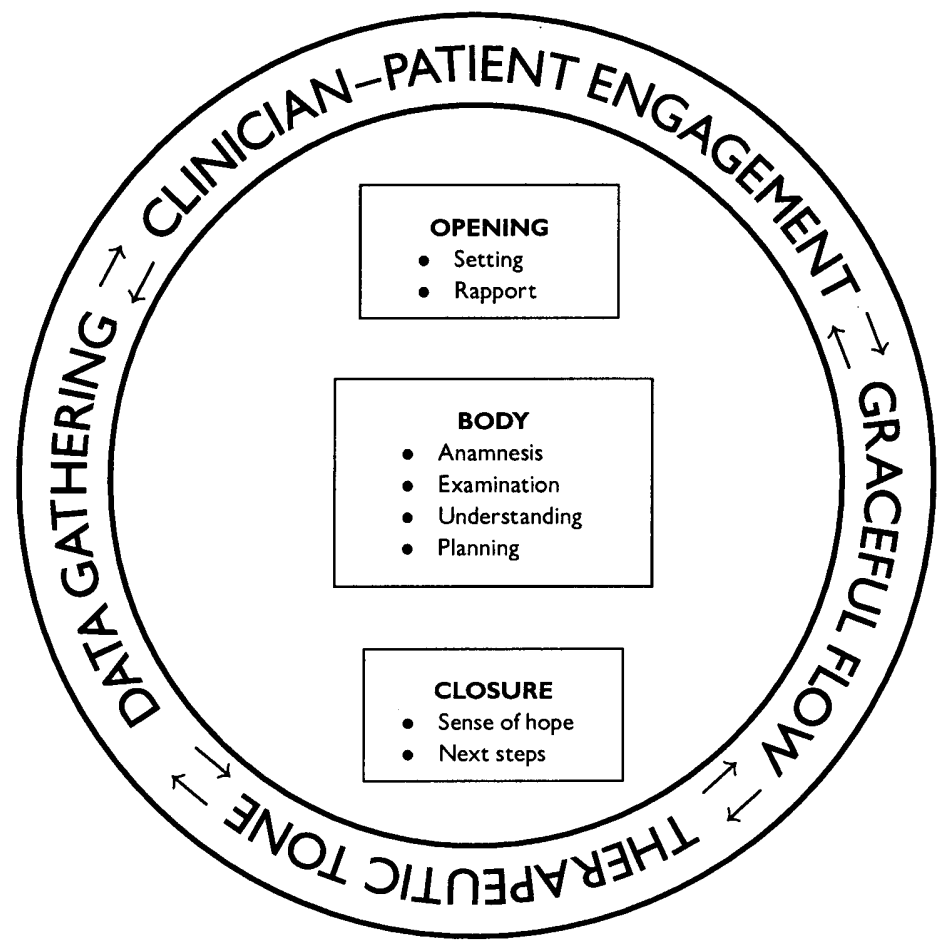

Fig. 2.I. The interviewing process. 
self-esteem, a sense of hope, cooperation, and clarity on goals, expected progress and the process to follow.

\section{FURTHER READING}

Anderson, A. K. \& Lynch, T. (1996) Listening. Oxford Oxford University Press.
Deniker, P. \& Féline, A. (1990) Le premier contact et l'observation in psychiatrie [The first contact and observation in psychiatry]. In Précis de Psychiatrie Clinique de l'Adulte (eds P. Deniker, T. Lempériere \& J. Guyotat), pp. 5-II. Paris: Masson.

Barcia-Salorio, D. \& Muñoz-Pérez, R. (1991) The interview in psychiatry. In The European Handbook of Psychiatry and Mental Health (ed. A. Seva), pp. 443-458. Saragossa: Saragossa University Press.
Shea, S. C.. (1988) Psychiatric Interviewing: The Art of Understanding (2nd edn). Philadelphia, PA: Saunders.

Ward, N. G. \& Stein, G. (1975) Reducing emotional distance: a new method of teaching interviewing skills. Journal of Medical Education, $\mathbf{5 0}$ 605-614. 